\title{
Feasibility Study of 1/3 Thorium-Plutonium Mixed Oxide Core
}

\author{
Cheuk Wah Lau, ${ }^{1}$ Henrik Nylén, ${ }^{1,2}$ Klara Insulander Björk, ${ }^{1,3}$ and Urban Sandberg ${ }^{2}$ \\ ${ }^{1}$ Division of Nuclear Engineering, Department of Applied Physics, Chalmers University of Technology, 41296 Gothenburg, Sweden \\ ${ }^{2}$ Ringhals $A B, 43285$ Väröbacka, Sweden \\ ${ }^{3}$ Thor Energy AS, Sommerrogaten 13-15, 0255 Oslo, Norway
}

Correspondence should be addressed to Cheuk Wah Lau; cheuk@nephy.chalmers.se

Received 16 December 2013; Revised 25 January 2014; Accepted 10 February 2014; Published 17 March 2014

Academic Editor: Arkady Serikov

Copyright (C) 2014 Cheuk Wah Lau et al. This is an open access article distributed under the Creative Commons Attribution License, which permits unrestricted use, distribution, and reproduction in any medium, provided the original work is properly cited.

\begin{abstract}
Thorium-plutonium mixed oxide (Th-MOX) fuel has become one of the most promising solutions to reduce a large and increasing plutonium stockpile. Compared with traditional uranium-plutonium mixed oxide (U-MOX) fuels, Th-MOX fuel has higher consumption rate of plutonium in LWRs. Besides, thorium based fuels have improved thermomechanical material properties compared with traditional U-MOX fuels. Previous studies on a full Th-MOX core have shown reduced efficiency in reactivity control mechanisms, stronger reactivity feedback, and a significantly lower fraction of delayed neutrons compared with a traditional uranium oxide (UOX) core. These problems complicate the implementation of a full Th-MOX core in a similar way as for a traditional U-MOX core. In order to reduce and avoid some of these issues, the introduction of a lower fraction of Th-MOX fuel in the core is proposed. In this study, one-third of the assemblies are Th-MOX fuel, and the rest are traditional UOX fuel. The feasibility study is based on the Swedish Ringhals-3 PWR. The results show that the core characteristics are more similar to a traditional UOX core, and the fraction of delayed neutrons is within acceptable limits. Moreover, the damping of axial xenon oscillations induced by control rod insertions is almost 5 times more effective for the 1/3 Th-MOX core compared with the standard core.
\end{abstract}

\section{Introduction}

Past decades of extensive utilization of LWRs have created a significant amount of plutonium. This plutonium could be either utilized in future fast reactor systems or stored in final repository. In the latter case, U-MOX cycles have been used to reduce the plutonium stockpile, but the uranium in $\mathrm{U}$ MOX fuels continuously generates new plutonium, making plutonium incineration less efficient. Consequently, other LWR-based methods have been proposed to decrease the plutonium stockpile, like mixing plutonium with thorium or other inert materials [1]. Many studies have shown that ThMOX fuels are very effective for plutonium incineration [27]. Besides the high plutonium consumption, the Th-MOX fuel material also has good thermomechanical properties, such as low thermal expansion coefficient, low fission-gas release, high thermal conductivity, and high melting temperature [8].
Steady state analyses have shown feasibility to use ThMOX fuel in a full Th-MOX PWR core but would require some modifications to the reactivity control systems, such as types and quantities of control rods, and enriched boron (B10) dissolved in the reactor coolant $[9,10]$. This is because the plutonium and thorium in Th-MOX contribute to a harder neutron spectrum making all the reactivity control systems less efficient. Thus, additional and more efficient neutron absorbing materials are required. Additionally, the fraction of delayed neutrons is lower in the Th-MOX fuel compared with UOX fuel, because the main fissile isotopes $\mathrm{Pu}-239$ and U-233 yield a lower fraction of delayed neutrons [11], which implies that a full Th-MOX core is more difficult to control during reactivity induced accidents. The reactivity feedback parameters in the Th-MOX core are more negative compared with the UOX core, making the current safety analyses inadequate. 
Some of the disadvantages in full Th-MOX cores are comparable to full U-MOX cores, such as reduced control rod worth and boron worth. However, previous studies have demonstrated that a core using 30-50\% U-MOX fuel with the rest being UOX fuel shows characteristics similar to those of traditional UOX cores $[12,13]$.

Full Th-MOX PWR cores have challenges and are demanding to implement. Therefore, in this study, a direct comparison between standard UOX core and a 1/3 Th-MOX core is made. Some of the key parameters are presented to understand the difficulties and benefits of the $1 / 3$ Th-MOX core.

\section{Models and Analysis Methods}

The two cores compared in this study, a $1 / 3$ Th-MOX core and a UOX core referred to as standard core, have some differences and similarities. The similarities are the Ringhals3 PWR model, fuel assembly geometries, and safety limit constraints. The differences are cycle length, number of fuel batches, fuel pellet compositions, boron concentration at beginning of cycle (BOC), and number of control rods. The standard and the 1/3 Th-MOX core have 12- and 15month cycle, respectively. The standard core has a 3-batch reloading scheme, while the $1 / 3 \mathrm{Th}$-MOX core has a 2-batch reloading scheme. The standard core uses natural boron in the reactor coolant, while the $1 / 3$ Th-MOX uses enriched boron to increase the proportion of the neutron absorber B10.

2.1. Fuel Assemblies. This study involves four different kinds of fuel assemblies: U, U-G, Th-MOX, and shielding assemblies. The shielding fuel assemblies are loaded closest to the reactor pressure vessel in order to protect the belt-line weld from the fast neutron flux [14]. The shielding fuel assemblies contain three types of rods: steel rods and low enriched and depleted uranium fuel rods. All the fuel assemblies have the same mechanical structure and geometry, except for the shielding assemblies in which 3 rows of fuel rods are substituted with stainless steel rods. The fuel assemblies have a $17 \times 17$ lattice with 264 fuel rods and 25 guide tubes. In the $\mathrm{U}$ fuel assemblies, all the fuel rods have $4.4 \%$ enriched uranium. The U-G fuel assembly also has $4.4 \%$ enriched uranium in most of the fuel rods, but 12 of the fuel rods contain gadolinium with $2.8 \%$ of enriched uranium, as shown in Figure 1. The standard core uses U, U-G, and shielding fuel assemblies, whereas the $1 / 3$ Th-MOX core uses Th-MOX, U, and $\mathrm{U}-\mathrm{G}$ fuel assemblies.

The Th-MOX fuel assembly is specially designed to be compatible with UOX fuel in the 1/3 Th-MOX core. For similar power and discharge burnup, UOX fuels require higher neutron flux compared with plutonium fuels. To achieve an even power distribution for a Th-MOX fuel assembly situated next to a UOX fuel assembly, additional fuel pellet zones are needed in the Th-MOX fuel assembly, as shown in Figure 2, which is similar to U-MOX fuel. The plutonium isotope vector used in the Th-MOX fuel is 2\% Pu-238, 53\% Pu-239, 25\% Pu-240, 15\% Pu-241, and 5\%

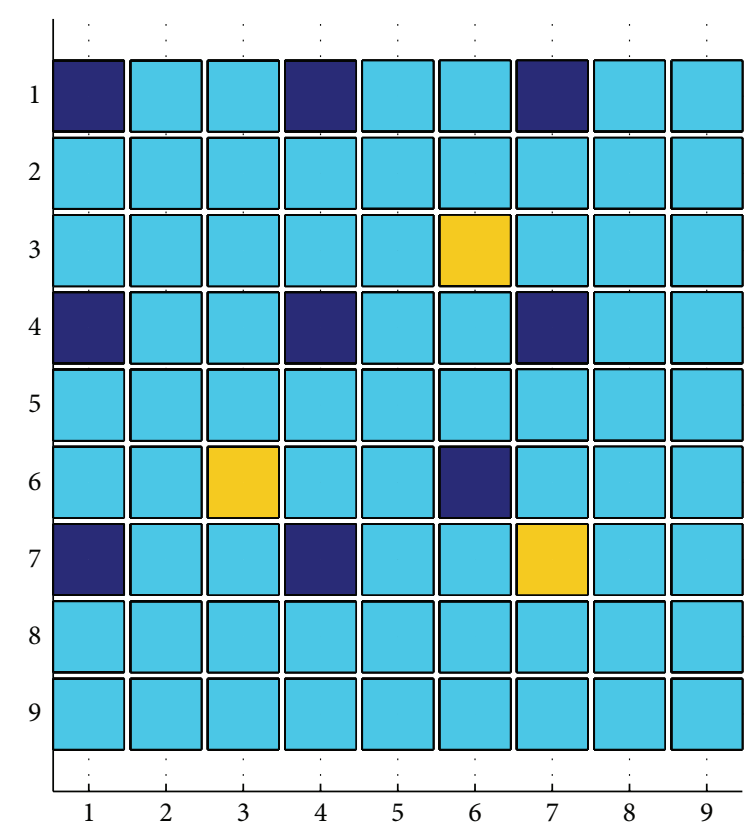

FIGURE 1: Lower right quarter of the $17 \times 17 \mathrm{U}-\mathrm{G}$ fuel assembly. The light blue color represents the $4.4 \%$ enriched uranium fuel rods. The yellow color represents the $2.8 \%$ enriched uranium with $6 \% \mathrm{Gd}_{2} \mathrm{O}_{3}$ fuel rods. The dark blue color represents the guide tubes.

$\mathrm{Pu}-242$. This plutonium isotope vector corresponds to light water fuel with a discharge burnup around $42 \mathrm{MWd} / \mathrm{kgHM}$ if reprocessed immediately [15]. The burnable absorber (BA) configuration used in Th-MOX fuel assembly is the integral fuel burnable absorber (IFBA). The choice of IFBA in ThMOX instead of gadolinium is motivated by the consequence of adding a third material to the fuel pellet composition, which would complicate the prediction of the thermal and mechanical properties.

2.2. Cores. The model used for simulation is the Swedish Ringhals-3 PWR with a 3-loop Westinghouse design producing 3135 MWth with 157 fuel assemblies. The standard core used in the simulation operates in a 12-month cycle, and each batch of the three-batch loading scheme consists of 48 fuel assemblies (20 U and $28 \mathrm{U}-\mathrm{G}$ fuel assemblies), as shown in Figure 3. There are 12 additional shielding fuel assemblies near the pressure vessel wall. The 1/3 Th-MOX core operates in a 15-month cycle and uses U, U-G, and ThMOX fuel assemblies, as shown in Figure 4. The core loading scheme alters between 80 and 76 new fuel assemblies for each batch, because of the quarter symmetry. Both cores have a low leakage loading pattern in order to achieve the highest possible discharge burnup of the fuel assemblies. The simulated cores have reached equilibrium conditions by reloading with the same quantities, type of fuel assemblies (FAs), and loading pattern for 7 cycles.

The $1 / 3$ Th-MOX core requires enriched boron $(30 \% \mathrm{~B}$ $10)$ in the reactor coolant, while natural boron $(19.8 \%$ B-10) is used in the standard core. Moreover, the standard core has 


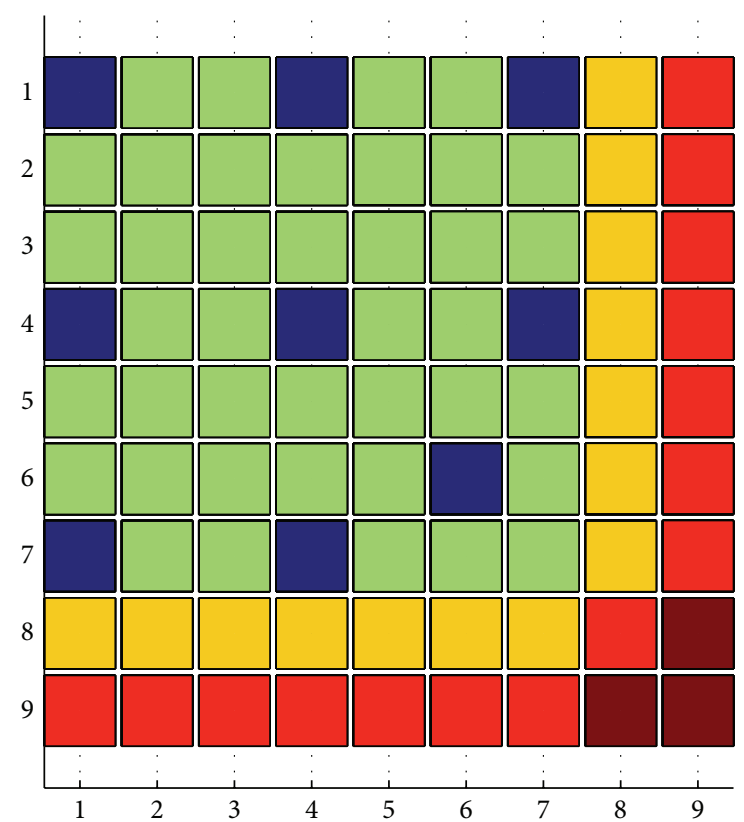

FIGURE 2: Lower right quarter of the $17 \times 17$ Th-MOX fuel assembly. The dark red color, light red color, yellow color, and green color represent the fuel rods that have $2.3 \%, 4.6 \%, 6.8 \%$, and $10.2 \%$ plutonium, respectively. The dark blue color represents the guide tubes.

48 control rods and 1/3 Th-MOX core requires additional 4 control rods.

2.3. Analysis Methods. The tools used in this study are CASMO-4E with the JEFF2.2 library, CMS Link, XIMAGE, SIMULATE-3, and SIMULATE-3K $[16,17]$. CASMO-4E is a two dimensional lattice code used to generate crosssection data. CMS Link was used to convert the data from CASMO-4E into XIMAGE, SIMULATE-3, and SIMULATE$3 \mathrm{~K}$ format. XIMAGE was used to optimize the core loading pattern. SIMULATE-3 and SIMULATE-3K are three dimensional nodal codes for steady state and transient simulations, respectively. The methodology of the analyses and the limits set in this study are based on a reload safety evaluation, licensed by the US NRC in the topical report WCAP-92724 [18].

\section{Results}

3.1. Infinite Multiplication Factor in Fuel Assemblies. In Figure 5, the infinite multiplication factor $\left(k_{\text {inf }}\right)$ as function of burnup is shown for the U-G and Th-MOX fuel assembly. As shown in the figure, the U-G fuel has higher $k_{\text {inf }}$ at beginning of life compared with the Th-MOX fuel assembly, because of the higher absorption cross-section of the fertile isotope Th-232 in the Th-MOX fuel assembly. However, the higher absorption cross-section causes higher production of the fissile isotope $\mathrm{U}-233$, which gives a positive contribution to the $k_{\text {inf }}$. Consequently, the decrease of $k_{\text {inf }}$ in the Th-MOX fuel assembly is comparatively slow.

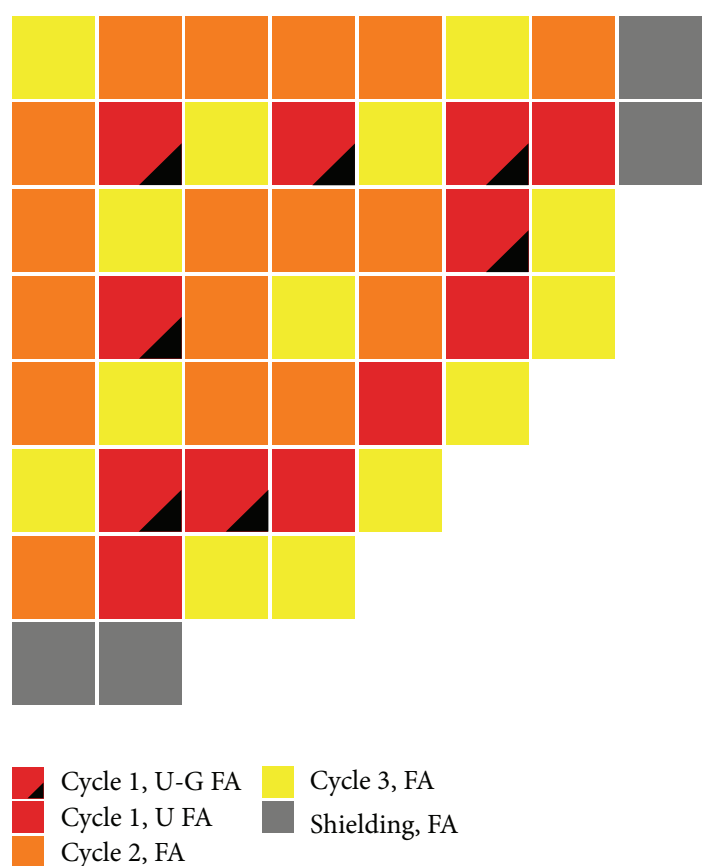

FIGURE 3: The figure shows the lower right corner of the standard core loading pattern.
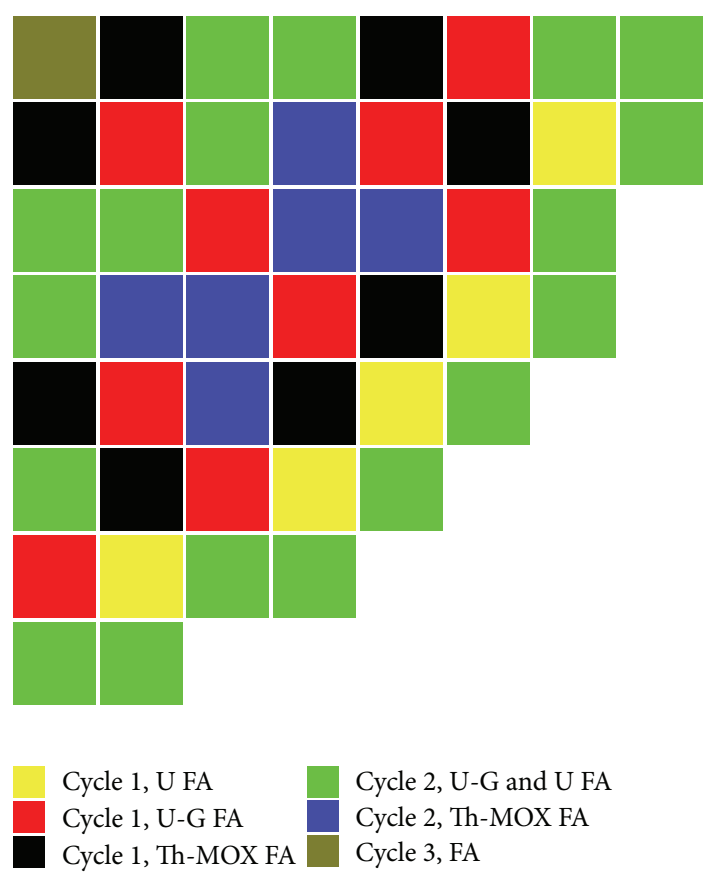

FIgURE 4: The figure shows the lower right corner of the Th-MOX core loading pattern.

The two fuel assemblies are using different kinds of BAs. The U-G fuel assembly is using gadolinium which suppresses $k_{\text {inf }}$ from beginning of life to $15 \mathrm{GWd} / \mathrm{MT}$. The strong suppression is caused by high efficiency in reducing the neutron flux around the absorber. After the complete depletion of gadolinium around $15 \mathrm{GWd} / \mathrm{MT}, k_{\text {inf }}$ decreases faster. The 


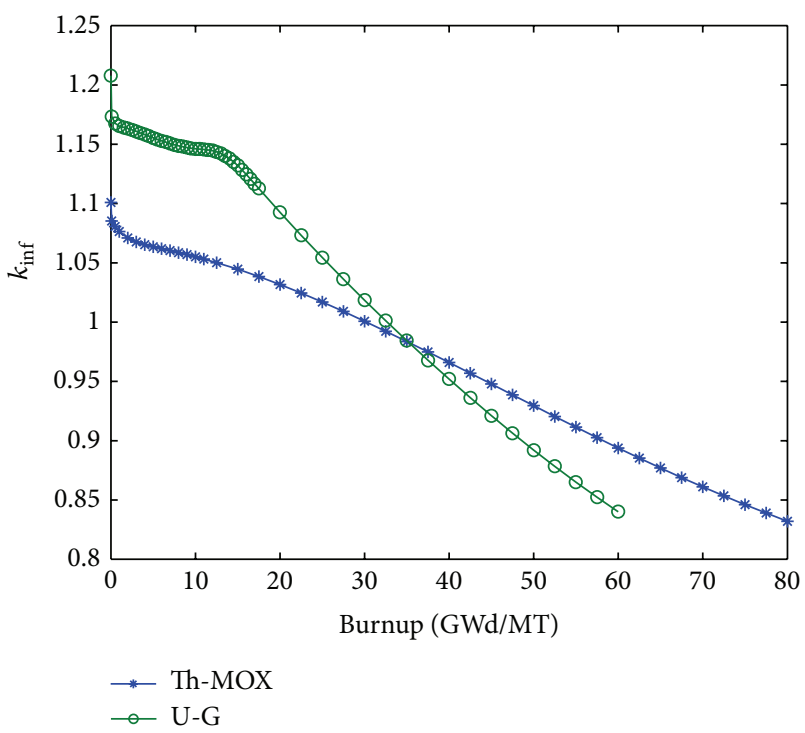

FIgURE 5: The $k_{\text {inf }}$ in the Th-MOX and U-G fuel assembly.

Th-MOX fuel assembly is using IFBA to reduce $k_{\text {inf }}$ at the beginning of life, which is depleted around $30 \mathrm{GWd} / \mathrm{MT}$, causing a comparatively slow reduction of $k_{\text {inf }}$ during this burnup interval.

3.2. Power Distribution. The results of the core power distribution calculations are divided into three parts: 2D horizontal, $1 \mathrm{D}$ axial, and 3D local peak power. In the 2D horizontal plane, the pin peak power shows the highest pin power normalized by the average pin power. In the $1 \mathrm{D}$ axial plane, the axial offset $(\mathrm{AO})$ shows the power distribution between the top and bottom halves of the core. Finally, the 3D local peak power shows the highest local power normalized by the average local power.

The pin peak power is within the limits for both cores. The 1/3 Th-MOX core has a slightly higher pin peak power compared with the standard core at BOC, as shown in Figure 6 . The reason is the mixture between plutonium and uranium fuel assemblies as mentioned above. The shift of pin peak power in the horizontal plane during the cycle is mostly caused by the burnup rate in each fuel region and the depletion of the BA. The BA is required to reduce the boron concentration and lower the pin peak power.

The description of the $1 \mathrm{D}$ axial power distribution is presented as AO. The definition of $\mathrm{AO}$ is given by

$$
\mathrm{AO}=\frac{P_{\text {top }}-P_{\text {bottom }}}{P_{\text {top }}+P_{\text {bottom }}},
$$

where $P_{\text {top }}$ and $P_{\text {bottom }}$ are the average power at the top and bottom halves of the core, respectively.

The $\mathrm{AO}$ in both cores is well within the $-15 \%$ to $15 \%$ range. The AO in the 1/3 Th-MOX core is closer to zero during most of the cycle compared with the standard core, concluding that the $1 / 3$ Th-MOX core has a more even power distribution in the axial plane. The standard core has a positive $\mathrm{AO}$ at $\mathrm{BOC}$ but has a negative $\mathrm{AO}$ for a longer part of the cycle, as shown

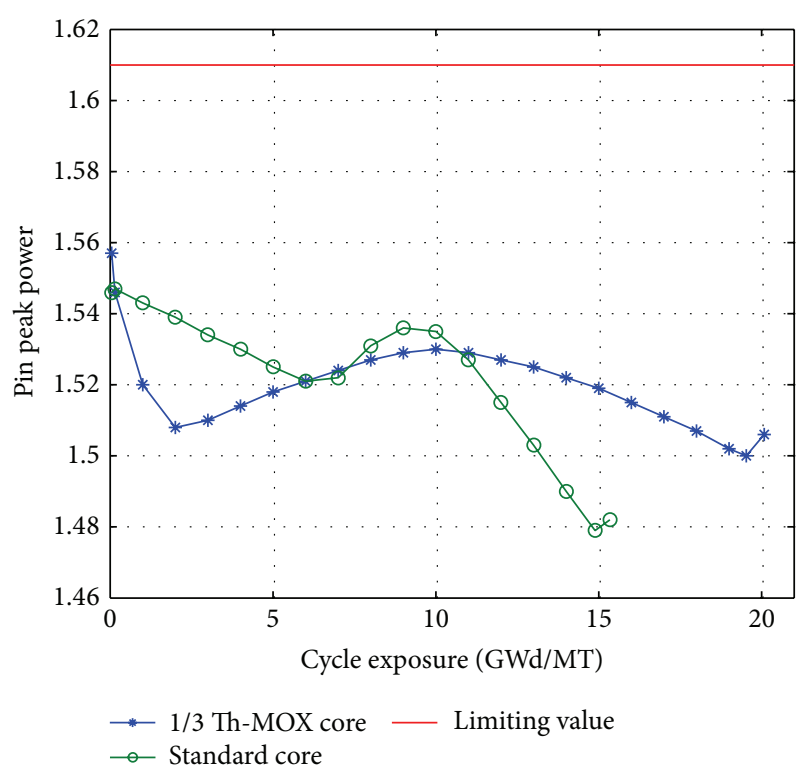

FIGURE 6: The pin peak power as function of burnup for the standard and $1 / 3$ Th-MOX core.

in Figure 7. The 1/3 Th-MOX core has a negative $\mathrm{AO}$ until the end of cycle (EOC). Both cores have positive AO at EOC, where the power is adjusted to $90 \%$ of full power. It should be noticed that the change at EOC is smaller in the 1/3 Th-MOX core, showing that the AO in Th-MOX core is less sensitive to power changes, implying an improved core power stability, both locally and globally.

The local peak power of both cores is within the limit during the whole cycle. The $1 / 3$ Th-MOX core has a slightly higher local peak power compared with the standard core. The standard core has a peak of local peak power at the middle of cycle corresponding to the complete depletion of gadolinium, while the 1/3 Th-MOX core has its peak at BOC, as shown in Figure 8.

The results of the core power distribution calculations are within the limits and show no significant differences between the standard and 1/3 Th-MOX cores.

3.3. The Damping of Axial Xenon Oscillations. Xenon oscillations appear as the xenon concentration, the iodine concentration, and the neutron flux are out of phase in two or more regions in the core. The most dominant oscillation for PWRs is the axial xenon oscillation and it has period from 15 to 30 hours. The core power axial stability is dependent on various parameters such as core size, power level, fuel composition, control rod positions, boron concentration, and reactivity feedback.

The simulation method used to analyze axial xenon oscillations is by simulating insertion of all control rods $53 \mathrm{~cm}$ into the core for 6 minutes and then withdrawing them back to normal positions. These maneuvers will reduce the power at the upper part of the core, while the total power will remain unaffected, and the xenon oscillation will start to appear. 
TABLE 1: Boron worth, shutdown margin, and max rod worth.

\begin{tabular}{lccc}
\hline Parameter & Limit & Standard core & 1/3 Th-MOX core \\
\hline Min boron worth $(\mathrm{pcm} / \mathrm{ppm})$ & $\geq-15$ & -7.96 & -9.94 \\
Max boron worth $(\mathrm{pcm} / \mathrm{ppm})$ & $\leq-5$ & -5.99 & -6.65 \\
Min SDM $(\mathrm{pcm})$ & 2000 & 2453 & 3243 \\
Max rod worth $(\mathrm{pcm})$ & - & 6433 & 7243 \\
\hline
\end{tabular}

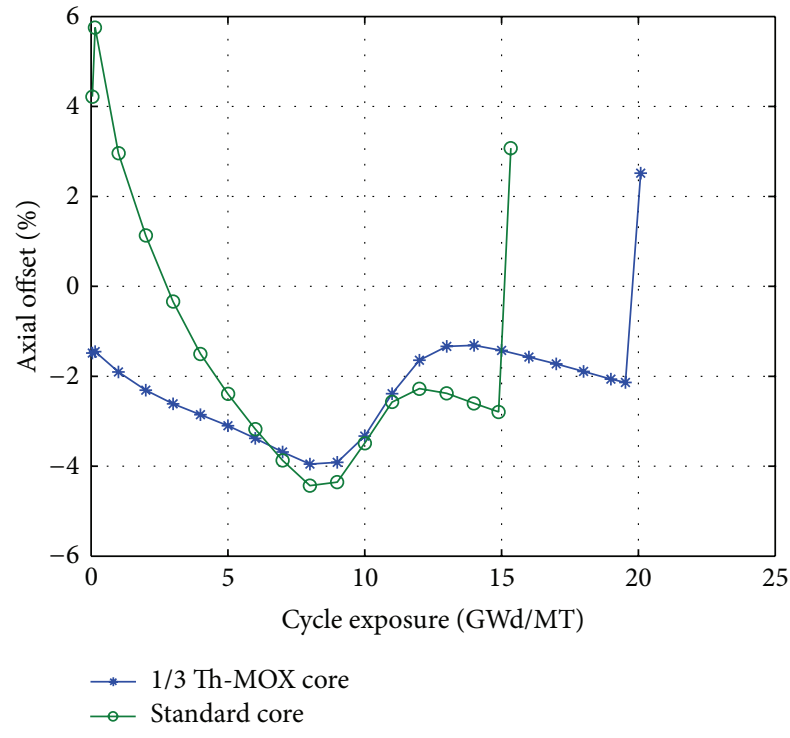

FIGURE 7: The axial offset as function of burnup for the standard and 1/3 Th-MOX core.

In Figure 9, more efficient damping and earlier stabilized AO are found in the 1/3 Th-MOX core compared with the standard core. The decay ratio calculated from the ratio of the amplitude peaks is 0.43 and 0.09 for the standard and $1 / 3$ ThMOX core, respectively. The improved decay ratio is mostly contributed by the thorium and plutonium. The presence of these isotopes will harden the neutron spectrum and improve the power stability. This demonstrates that the Th-MOX fuel has a high impact on improving the stability of the core, which could make it possible to be used for load-following purposes.

3.4. Boron Concentration and Control Rods. The dissolved boron in 1/3 Th-MOX core has 50\% higher enrichment of B-10 compared with the standard core. Without the higher enrichment, the boron concentration in the moderator will exceed the practical operation limit. The boron concentration in the $1 / 3$ Th-MOX core is lower at BOC compared with the standard core, although the B-10 concentration is higher. Since the $1 / 3$ Th-MOX has a longer cycle, the boron concentration will decrease slower compared with the standard core, as shown in Figure 10.

In Table 1, the maximum and minimum boron worth are shown and are within the limits for both cores. Without the B-10 enrichment, the $1 / 3$ Th-MOX core will exceed the maximum allowed boron concentration. However, the maximum boron worth and the boron concentration indicate

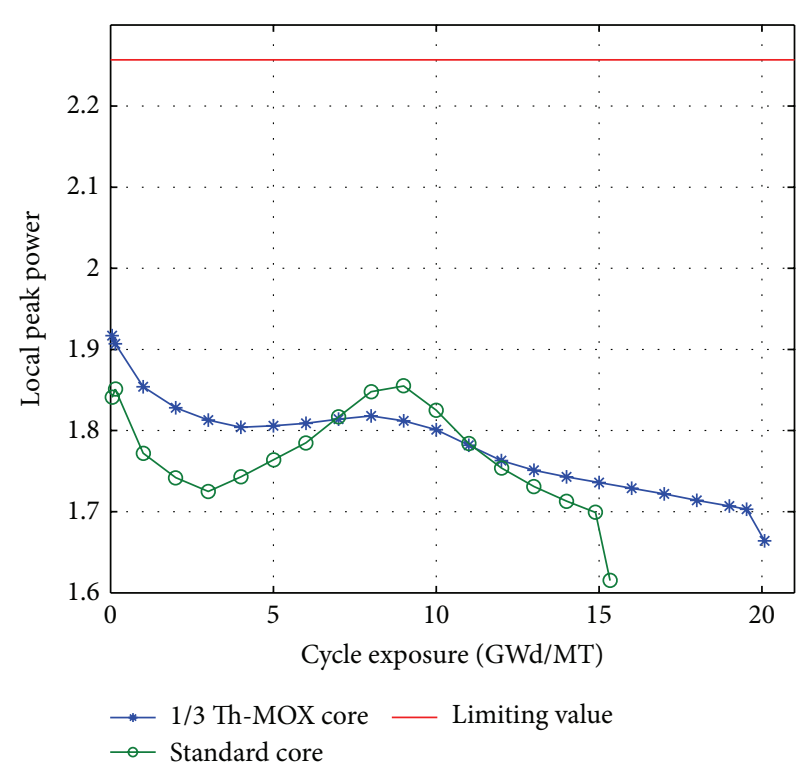

FIgURE 8: The local peak power as function of burnup for the standard and 1/3 Th-MOX core.

that it is possible to decrease the enrichment of B-10, but not to levels as low as natural boron.

The shutdown margin (SDM) is the margin to criticality when all control rods except for the control rod with the highest rod worth are inserted into the core. The SDM in the 1/3 Th-MOX core shows a larger safety margin compared with the standard core since 4 additional control rods are used in the $1 / 3$ Th-MOX core, as shown in Table 1 . Without the extra control rods, the SDM in 1/3 Th-MOX core would fall short of the safety limit.

3.5. Reactivity Feedback. The moderator temperature coefficient (MTC) of reactivity is highest at BOC. In Ringhals-3, the MTC is not required to be negative. The highest MTC is at BOC hot zero power (HZP) with all rods out (ARO). The standard core MTC is negative at BOC but positive in the $1 / 3$ Th-MOX core, mainly because of the high amount of B-10 in the reactor coolant. The boron concentration could be decreased by increasing BAs in the fuel. The moderator density coefficient (MDC) is lowest at EOC, and both of the cores are well within the limit.

The isothermal temperature coefficient (ITC) of reactivity is a combination between the MTC and Doppler temperature coefficient (DTC) of reactivity as the temperature is equally perturbed in the fuel and moderator. The ITC is highest at $\mathrm{BOC}$ and must be negative during the whole cycle. The $1 / 3$ 


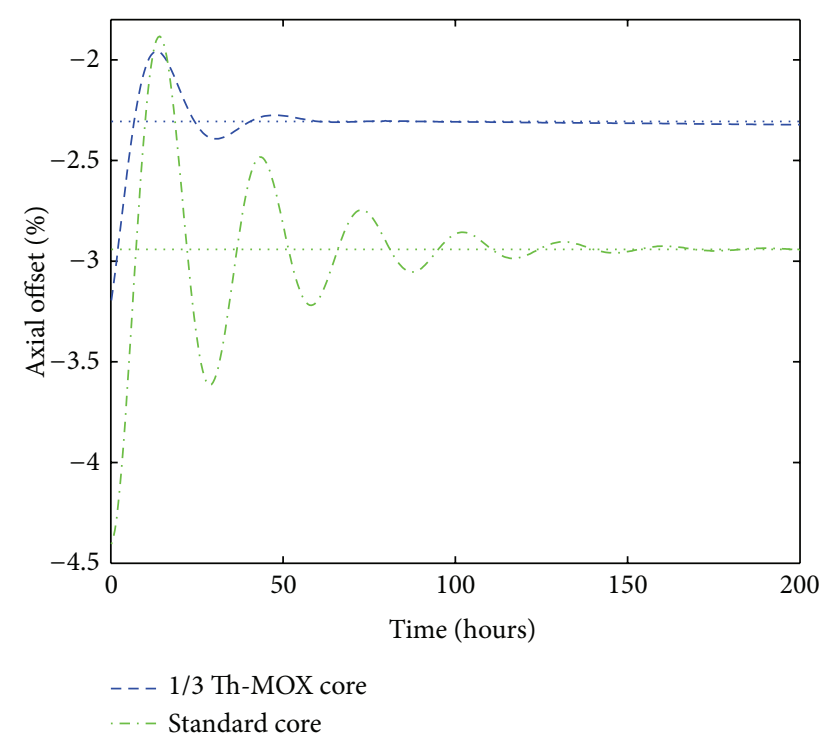

FIGURE 9: The AO oscillation as function of time in the standard and 1/3 Th-MOX core.

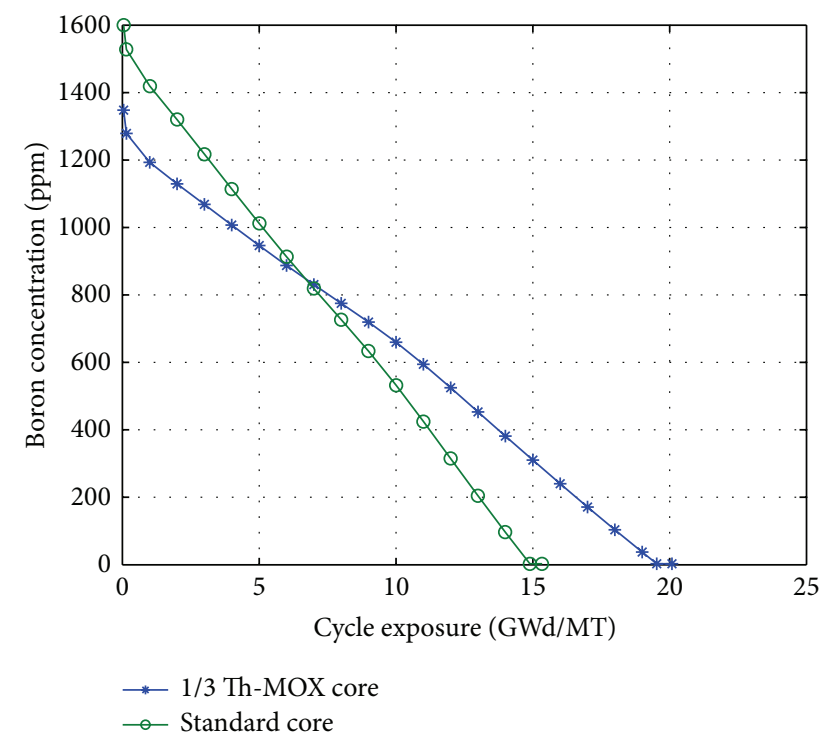

Figure 10: The boron concentration as function of burnup in both of the cores.

Th-MOX core has less margins to the ITC limit compared with the standard core because of the high MTC, as shown in Table 2.

In Table 3, it is shown that the $1 / 3$ Th-MOX has lower DTC and Doppler power coefficient (DPC) of reactivity compared with the standard core. The lower DTC and DPC in the $1 / 3 \mathrm{Th}$ MOX are consistent with other thorium based PWR cores [9, 10]. The minimum DTC and the minimum DPC at $0 \%$ power EOC have exceeded their limits by a small amount. However, the core should be safe to operate in spite of these marginally exceeded limits because of the existing large margins within current safety analyses.
3.6. Fraction of Delayed Neutrons. The fraction of delayed neutrons is important for the understanding of the core's time-dependent behavior caused by reactivity perturbations. The fissile isotope U-235 has a significantly larger yield of delayed neutrons compared with other fissile isotopes, such as U-233 and Pu-239. By using a lower amount of Th-MOX fuel assemblies in the 1/3 Th-MOX core, the fraction of delayed neutrons will be comparatively higher than that for a full Th-MOX core. The 1/3 Th-MOX core has a lower fraction of delayed neutrons compared with a standard core but is within the limits for the system, as shown in Table 4.

3.7. Plutonium Consumption. As previously mentioned, several studies show that Th-MOX fuels are effective for plutonium incineration. For the particular case of the analyzed $1 / 3$ Th-MOX core, a comparison is done with the case of a full ThMOX core and a normal UOX core. The calculated plutonium consumption rates in terms of $\mathrm{kg} / \mathrm{TWh}$ for these cores are also compared with the literature data for a $30 \% \mathrm{U}-\mathrm{MOX}$ core and a full U-MOX core.

The UOX core produces $273.8 \mathrm{~kg}$ plutonium per reactoryear, while the $1 / 3$ Th-MOX and full Th-MOX cores consume $148.4 \mathrm{~kg}$ and $1064.8 \mathrm{~kg}$ plutonium per reactor-year, respectively. Pu-239 is the most dominant isotope in the plutonium vector and has the highest production and consumption rate in the cores, as shown in Table 5. In the UOX core, Pu-239 represents half of the plutonium produced. In the $1 / 3 \mathrm{Th}$ MOX core, only $\mathrm{Pu}-239$ and $\mathrm{Pu}-240$ will be consumed; the other plutonium isotopes have instead a net production. A full Th-MOX core [9] has about 7 times higher plutonium consumption rate compared with the 1/3 Th-MOX core. Moreover, only the $\mathrm{Pu}-242$ isotope has a net production in the full Th-MOX core. The reason for the relatively low incineration rate of plutonium in the $1 / 3 \mathrm{Th}-\mathrm{MOX}$ is that $2 / 3$ of the core still uses UOX fuel and produces new plutonium. In Table 6, comparison of the $1 / 3 \mathrm{Th}-\mathrm{MOX}$ core and the $30 \%$ U-MOX core shows that the net consumption rates of plutonium are $16 \mathrm{~kg} / \mathrm{TWh}$ and $1 \mathrm{~kg} / \mathrm{TWhe}$ [1], respectively. This demonstrates that plutonium incineration is more efficient in Th-MOX cores compared with U-MOX cores.

3.8. The Fuel Assembly Isotopic Concentrations. In the $1 / 3$ Th-MOX core, the Th-MOX fuel assembly discharge burnup is between 40 and $50 \mathrm{GWd} / \mathrm{tHM}$. In Figure 11, the Th-232 content at the beginning of life (BOL) and $50 \mathrm{GWd} / \mathrm{tHM}$ is 92 and 89.5 weight percentages of the heavy metals, respectively. The consumption of Th-232, which is converted into U-233, is about 2-2.5 weight percentages at current discharge burnup.

The main fissile isotopes in the Th-MOX fuel assembly are $\mathrm{U}-233, \mathrm{Pu}-239$, and $\mathrm{Pu}-241$. There is no U-233 at BOL, but it will increase to about 1.4 weight percentages at $50 \mathrm{GWd} / \mathrm{tHM}$, as shown in Figure 12. The content of $\mathrm{Pu}-239$ decreases rapidly from 4.2 to 0.6 weight percentages, because there is no production of $\mathrm{Pu}-239 \mathrm{Pu}-240$ constitutes about 2 and 1.3 weight percentages at $\mathrm{BOL}$ and $50 \mathrm{GWd} / \mathrm{tHM}$, respectively. $\mathrm{Pu}-242$ is the only plutonium isotope that increases with burnup, as shown in Figure 13. 
TABLE 2: The reactivity feedback MTC, MDC, and ITC.

\begin{tabular}{lccc}
\hline Parameter & Limit & Standard core & $1 / 3$ Th-MOX core \\
\hline Max MTC $\left(\right.$ BOC HZP ARO) $\left(\mathrm{pcm} /{ }^{\circ} \mathrm{C}\right)$ & - & -1.37 & 1.8 \\
$\operatorname{Max}$ MDC $\left(\mathrm{EOC}\right.$ HFP ARI) $\left(\Delta k / k / \mathrm{g} / \mathrm{cm}^{3}\right)$ & $\leq 0.50$ & 0.42 & 0.40 \\
$\operatorname{Max}$ ITC $\left(\mathrm{pcm} /{ }^{\circ} \mathrm{C}\right)$ & $<0.0$ & -4.60 & -1.68 \\
\hline
\end{tabular}

TABLE 3: The reactivity feedback DTC and DPC.

\begin{tabular}{lccc}
\hline Parameter & Limit & Standard core & $1 / 3$ Th-MOX core \\
\hline Min DTC $\left(\mathrm{pcm} /{ }^{\circ} \mathrm{C}\right)$ & $\geq-4.00$ & -3.73 & $-4.124($ violation $)$ \\
Max DTC $\left(\mathrm{pcm} /{ }^{\circ} \mathrm{C}\right)$ & $\leq-1.70$ & -2.11 & -2.253 \\
Min DPC $(100 \%$ power $)(\mathrm{pcm} / \%)$ & $\geq-21.00$ & -15.91 & -17.05 \\
Max DPC $(100 \%$ power $)(\mathrm{pcm} / \%)$ & $\leq-6.50$ & -10.17 & -10.93 \\
Min DPC $(0 \%$ power$)(\mathrm{pcm} / \%)$ & -30.00 & -28.21 & -31.25 (violation) \\
Max DPC $(0 \%$ power $)(\mathrm{pcm} / \%)$ & -10.00 & -15.80 & -15.71 \\
\hline
\end{tabular}

TABLE 4: Fraction of delayed neutrons.

\begin{tabular}{lccc}
\hline Parameter & Limit & Standard core & $1 / 3$ Th-MOX core \\
\hline $\operatorname{Max} \beta_{\text {eff }}$ BOC $(\mathrm{pcm})$ & $\leq 720$ & 645 & 560 \\
$\operatorname{Min} \beta_{\text {eff }}$ EOC $(\mathrm{pcm})$ & $\geq 430$ & 502 & 452 \\
\hline
\end{tabular}

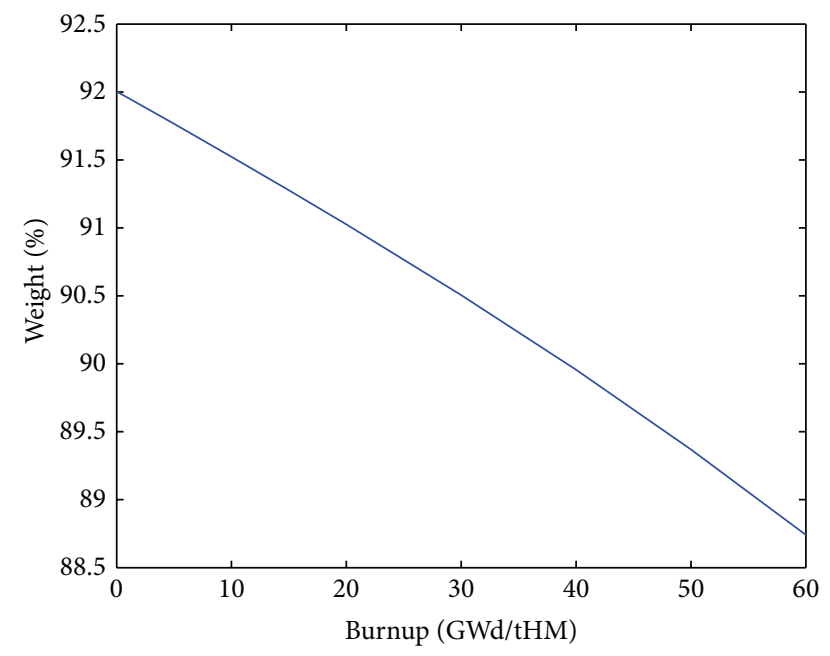

- Th-232

Figure 11: The amount of Th-232 in the Th-MOX fuel assembly.

\section{Discussion}

Using Th-MOX fuel will alter the core characteristics, such as a reduction of the control rod and boron worth. This is due to the harder neutron spectrum caused by the presence of plutonium and thorium. In order to compensate for this effect, enrichment of B-10 from $19.8 \%$ to $30 \%$ in the dissolved boron and an addition of 4 control rods for ensuring sufficient SDM are required. These modifications are feasible and straightforward. Instead of adding new control rods, it is possible to change to more effective control rods, from silverindium-cadmium to boron carbide control rods.

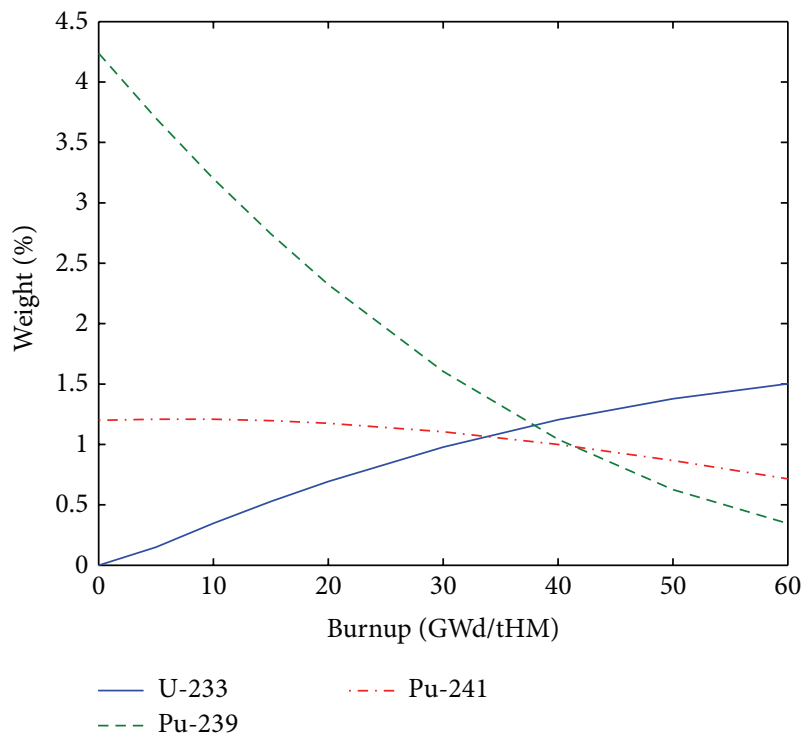

FIgURE 12: The amount of the fissile isotopes U-233, Pu-239, and Pu241 in the Th-MOX fuel assembly.

The main differences after the necessary modifications are the reactivity feedback coefficients. The MTC is positive at BOC, which is allowed for the Ringhals-3 core, and the ITC is negative during the cycle and fulfills the ITC safety limit. Moreover, it is possible to reduce the MTC by adding more BAs. The two reactivity feedback coefficients, DTC and DPC, are exceeding the transient-based limits and require new evaluations in order to fully comply with the reactor safety requirements. This would require new transient analysis based on the $1 / 3$ Th-MOX core reactivity feedback range. However, with the large built-in safety margins in current safety analyses for the reference UOX core and the small changes of reactivity feedback parameters compared with a UOX core, it is expected that a $1 / 3$ Th-MOX core shows acceptable results in full transient analyses.

The damping of axial xenon oscillations was shown to be almost 5 times more efficient in the 1/3 Th-MOX core 
TABLE 5: The plutonium consumption for UOX, 1/3 Th-MOX, and full Th-MOX core.

\begin{tabular}{|c|c|c|c|c|c|c|}
\hline & $\mathrm{Pu}-238$ & $\mathrm{Pu}-239$ & $\mathrm{Pu}-240$ & $\mathrm{Pu}-241$ & $\mathrm{Pu}-242$ & Total $\mathrm{Pu}$ \\
\hline \multicolumn{7}{|l|}{ UOX core } \\
\hline $\mathrm{BOC}(\mathrm{kg})$ & 4.5 & 273.9 & 82.0 & 52.0 & 14.4 & 426.8 \\
\hline EOC (kg) & 11.2 & 413.2 & 141.9 & 92.2 & 32.3 & 690.8 \\
\hline Consumption per cycle (kg) & -6.7 & -139.3 & -59.9 & -40.2 & -18.0 & -264.1 \\
\hline Consumption per reactor-year (kg) & -6.9 & -144.4 & -62.1 & -41.6 & -18.6 & -273.8 \\
\hline Relative consumption per year (\%) & -153.9 & -52.7 & -75.7 & -80.1 & -129.8 & -39.6 \\
\hline \multicolumn{7}{|l|}{ 1/3 Th-MOX core } \\
\hline BOC $(\mathrm{kg})$ & 32.7 & 784.7 & 428.7 & 267.6 & 99.8 & 1613.6 \\
\hline EOC (kg) & 34.8 & 575.4 & 409.4 & 272.2 & 135.1 & 1427.0 \\
\hline Consumption per cycle (kg) & -2.1 & 209.3 & 19.3 & -4.6 & -35.3 & 186.7 \\
\hline Consumption per reactor-year $(\mathrm{kg})$ & -1.7 & 166.4 & 15.4 & -3.6 & -28.0 & 148.4 \\
\hline Relative consumption per year (\%) & -5.2 & 21.2 & 3.6 & -1.4 & -28.1 & 10.4 \\
\hline \multicolumn{7}{|l|}{ Full Th-MOX core } \\
\hline BOC $(\mathrm{kg})$ & 165.5 & 3019.3 & 1973.7 & 1216.3 & 496.2 & 6871.0 \\
\hline EOC (kg) & 165.1 & 1812.4 & 1742.3 & 1106.2 & 554.7 & 5380.6 \\
\hline Consumption per cycle (kg) & 0.5 & 1206.9 & 231.4 & 110.1 & -58.6 & 1490.3 \\
\hline Consumption per reactor-year (kg) & 0.3 & 862.4 & 165.3 & 78.7 & -41.8 & 1064.8 \\
\hline Relative consumption per year (\%) & 0.2 & 28.6 & 8.4 & 6.5 & -8.4 & 19.8 \\
\hline
\end{tabular}

TABLE 6: The plutonium consumption rate.

\begin{tabular}{lc}
\hline & $\begin{array}{c}\text { Plutonium consumption rate } \\
(\mathrm{kg} / \text { TWhe })\end{array}$ \\
\hline UOX core & -30 \\
1/3 Th-MOX core & 16 \\
Full Th-MOX core & 116 \\
30\% U-MOX core $[1]$ & 1 \\
Full U-MOX core $[1]$ & 62 \\
\hline
\end{tabular}

compared with the standard core. This property could be very useful for load-following purposes.

In a full Th-MOX core, the delayed neutron fraction was substantially lower compared with a standard UOX core [9], but the 1/3 Th-MOX core fulfills the required minimum fraction of delayed neutrons.

The $1 / 3$ Th-MOX core has a considerable plutonium incineration, because the Th-MOX fuel has higher plutonium incineration rate compared with the U-MOX fuel, whereas in the $30 \%$ U-MOX core, there is almost no net plutonium consumption. For the full MOX cores, we see that the full ThMOX core has about 2 times higher plutonium incineration rate compared with full U-MOX core.

For the further handling of the spent Th-MOX fuel, one possibility is reprocessing. The THOREX process was developed at Oak Ridge National Laboratory in the USA and has been further developed at Bhabha Atomic Research Center in India; see, for example, [19]. Due to the relative immaturity and the low solubility of $\mathrm{ThO}_{2}$, the results are not as good as those for the PUREX process. However, a few alternative approaches exist $[20,21]$. The plutonium in spent Th-MOX fuel has a very low fissile content and is thus very unattractive for weapons usage, which is a benefit from a

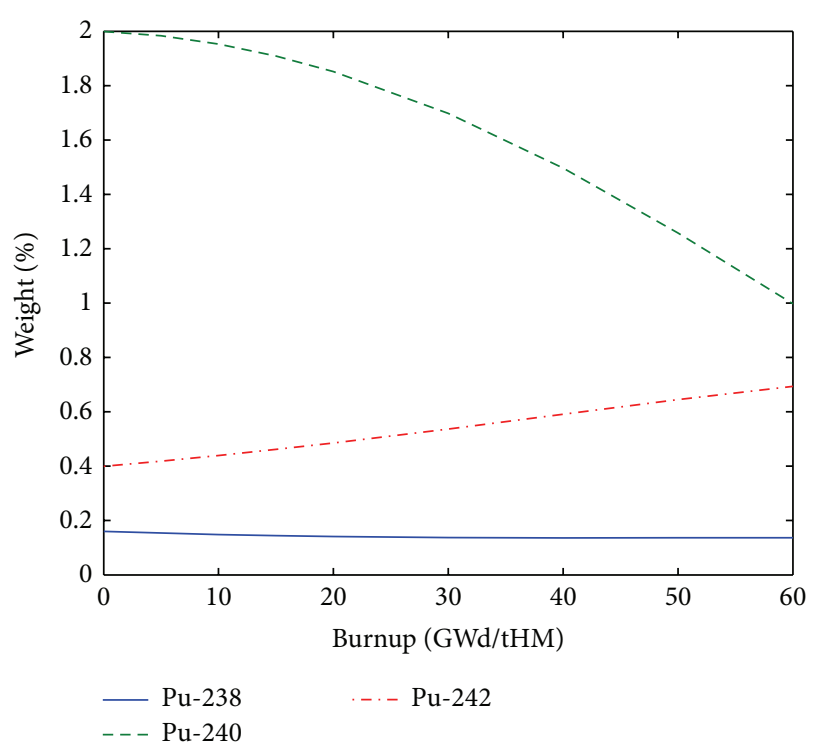

Figure 13: The amount of $\mathrm{Pu}-238, \mathrm{Pu}-240$, and $\mathrm{Pu}-242$ in the ThMOX fuel assembly.

proliferation point of view. However, it puts no limits to its use as a fuel for the fast reactors which may be deployed in the future. The situation is similar for the produced uranium. The U-233 is very attractive as a fuel for future reactors such as the thorium fuelled molten salt reactor [22], but the high fraction of U-232 accompanying the U-233 makes the material difficult to handle for manufacture of nuclear fuel and weapons alike.

When stored (permanently or temporarily), the beneficial chemical properties of the $\mathrm{ThO}_{2}$ matrix (lower solubility and lower fission product migration rates) seem to indicate that 
Th-MOX fuel would constitute a smaller risk than uranium based fuels [21].

In addition to the differences investigated and discussed in this paper, there are numerous differences between ThMOX, U-MOX, and UOX fuels related to mining and processing of the raw materials and fuel manufacture. The supply of thorium is vastly greater than that of uranium in the Earth's crust [21], and large stockpiles are already available above ground [23]. The manufacture route of Th-MOX is expected to be similar to that of U-MOX. However, the technology is still immature, which indicates higher manufacturing costs initially.

\section{Conclusions}

The safety aspects of introducing Th-MOX fuel in PWRs have been demonstrated for both a full Th-MOX core $[9,10]$ and a core containing 1/3 Th-MOX fuel in combination with ordinary UOX fuel. It has been shown that the basic safety limits are contained in both cases, but the lower amount of plutonium loaded in the $1 / 3$ Th-MOX core compared with a full Th-MOX core will result in a lower consumption rate of plutonium. However, the lower requirements of control rods and enriched boron, higher fraction of delayed neutrons, reactivity feedback more similar to that of a UOX core, and higher plutonium incineration compared with 30\% U-MOX core make the implementation of the $1 / 3$ Th-MOX core more attractive for initiating plutonium incineration in currently operating commercial LWRs. Additionally, the damping of axial xenon oscillations is more effective for the 1/3 Th-MOX core compared with the standard core. The strategy of using 1/3 Th-MOX leads to a cheaper and easier way to start using Th-MOX fuel assemblies in the near future for reducing the plutonium stockpile.

\section{Nomenclature}

$\begin{array}{ll}\text { AO: } & \text { Axial offset } \\ \text { ARO: } & \text { All rods out } \\ \text { BA: } & \text { Burnable absorber } \\ \text { BOC: } & \text { Beginning of cycle } \\ \text { BOL: } & \text { Beginning of life } \\ \text { DPC: } & \text { Doppler power coefficient of reactivity } \\ \text { DTC: } & \text { Doppler temperature coefficient of reactivity } \\ \text { EOC: } & \text { End of cycle } \\ \text { FA: } & \text { Fuel assembly } \\ \text { HZP: } & \text { Hot zero power } \\ \text { IFBA: } & \text { Integral fuel burnable absorber } \\ \text { ITC: } & \text { Isothermal temperature coefficient of reactivity } \\ k_{\text {inf }}: & \text { Infinite multiplication factor } \\ \text { MDC: } & \text { Moderator density coefficient } \\ \text { MTC: } & \text { Moderator temperature coefficient of reactivity } \\ \text { SDM: } & \text { Shutdown margin } \\ \text { Th-MOX: } & \text { Thorium-plutonium mixed oxide } \\ \text { U-MOX: } & \text { Uranium-plutonium mixed oxide } \\ \text { UOX: } & \text { Uranium oxide. }\end{array}$

\section{Conflict of Interests}

The authors declare that there is no conflict of interests regarding the publication of this paper.

\section{Acknowledgments}

Vattenfall AB, Oskarshamns Kraftgrupp AB (OKG AB), and Swedish Centre for Nuclear Technology (SKC) are acknowledged for the financial support, as well as Ringhals AB for the scientific and technical support. Support from the Norwegian Research Council was provided through the industrial Ph.D. program.

\section{References}

[1] R. P. C. Schram and F. C. Klaassen, "Plutonium management with thorium-based fuels and inert matrix fuels in thermal reactor systems," Progress in Nuclear Energy, vol. 49, no. 8, pp. 617-622, 2007.

[2] K. D. Weaver and J. S. Herring, "Performance of thorium-based mixed-oxide fuels for the consumption of plutonium in current and advanced reactors," Nuclear Technology, vol. 143, no. 1, pp. 22-36, 2003.

[3] E. Shwageraus, P. Hejzlar, and M. S. Kazimi, "Use of thorium for transmutation of plutonium and minor actinides in PWRs," Nuclear Technology, vol. 147, no. 1, pp. 53-68, 2004.

[4] H. R. Trellue, C. G. Bathke, and P. Sadasivan, "Neutronics and material attractiveness for PWR thorium systems using monte carlo techniques," Progress in Nuclear Energy, vol. 53, no. 6, pp. 698-707, 2011.

[5] K. Insulander Björk, V. Fhager, and C. Demazirère, "Comparison of thorium-based fuels with different fissile components in existing boiling water reactors," Progress in Nuclear Energy, vol. 53, no. 6, pp. 618-625, 2011.

[6] B. A. Lindley and G. T. Parks, "The performance of closed reactor grade plutonium-thorium fuel cycles in reducedmoderation pressurized water reactors," Annals of Nuclear Energy, vol. 47, pp. 192-203, 2012.

[7] K. Insulander Björk, "A BWR fuel assembly design for efficient use of plutonium in thorium-plutonium fuel," Progress in Nuclear Energy, vol. 65, pp. 56-63, 2013.

[8] C. Cozzo, D. Staicu, J. Somers, A. Fernandez, and R. J. M. Konings, "Thermal diffusivity and conductivity of thoriumplutonium mixed oxides," Journal of Nuclear Materials, vol. 416, no. 1-2, pp. 135-141, 2011.

[9] K. Insulander Björk, C. W. Lau, H. Nylén, and U. Sandberg, "Study of thorium-plutonium fuel for possible operating cycle extension in PWRs," Science and Technology of Nuclear Installations, vol. 2013, Article ID 867561, 8 pages, 2013.

[10] E. Fridman and S. Kliem, "Pu recycling in a full Th-MOX PWR core. Part I: steady state analysis," Nuclear Engineering and Design, vol. 241, no. 1, pp. 193-202, 2011.

[11] J. R. Lamarsh, Introduction to Nuclear Reactors Theory, chapter 3, American Nuclear Society, La Grange Park, Ill, USA, 2002.

[12] H. R. Trellue, "Safety and neutronics: a comparison of MOX vs $\mathrm{UO}_{2}$ fuel," Progress in Nuclear Energy, vol. 48, no. 2, pp. 135-145, 2006.

[13] R. J. Fetterman, "AP1000 core design with 50\% MOX loading," Annals of Nuclear Energy, vol. 36, no. 3, pp. 324-330, 2009. 
[14] U. Sandberg, H. Nylén, J. Roudén, P. Efsing, and J. Marten, "Shielding fuel assemblies used to protect the beltline weld of the reactor pressure vessel from fast neutron radiation in Ringhals unit 3 and 4," in Proceedings of the International Conference on the Physics of Reactors (PHYSOR '10), pp. 15341540, May 2010.

[15] "Plutonium," World Nuclear Association, 2009, http://www .world-nuclear.org/info/inf15.html.

[16] "CASMO-4E: Extended Capability CASMO-4-User's Manual," Studsvik Scandpower report SSP-09/442-U, 2009.

[17] “SIMULATE-3 User's Manual," STUDSVIK/SOA-95/15-REV $0,1995$.

[18] US Nuclear Regulatory Commission, "Westinghouse reload evaluation methodology," Tech. Rep. WCAP-9272, US Nuclear Regulatory Commission, 1978.

[19] P. K. Dey and N. K. Bansal, "Spent fuel reprocessing: a vital link in Indian nuclear power program," Nuclear Engineering and Design, vol. 236, no. 7-8, pp. 723-729, 2006.

[20] N. Sato and A. Kirishima, "Separation of thorium and uranium by sulfide method," Energy Procedia, vol. 7, pp. 444-448, 2011.

[21] Thorium Fuel Cycle-Potential Benefits and Challenges, IAEA, Vienna, Austria, 2005.

[22] S. Delpech, E. Merle-Lucotte, D. Heuer et al., "Reactor physic and reprocessing scheme for innovative molten salt reactor system," Journal of Fluorine Chemistry, vol. 130, no. 1, pp. 11-17, 2009.

[23] J. B. Hedrick, “Thorium," in U.S. Geological Survey Minerals Yearbook, 2004. 


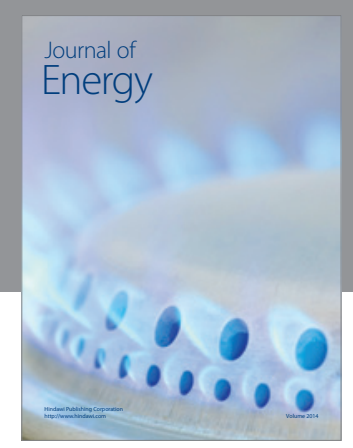

Journal of

Industrial Engineering
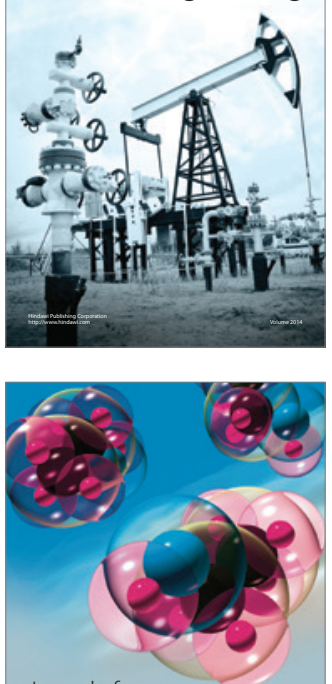

Fuels
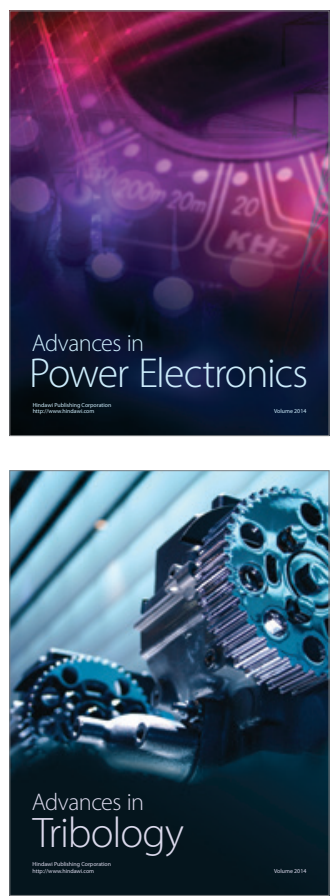

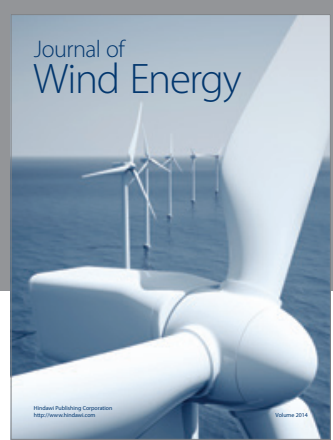

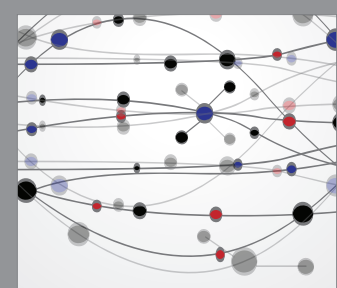

The Scientific World Journal

Submit your manuscripts at http://www.hindawi.com

Journal of

Structures
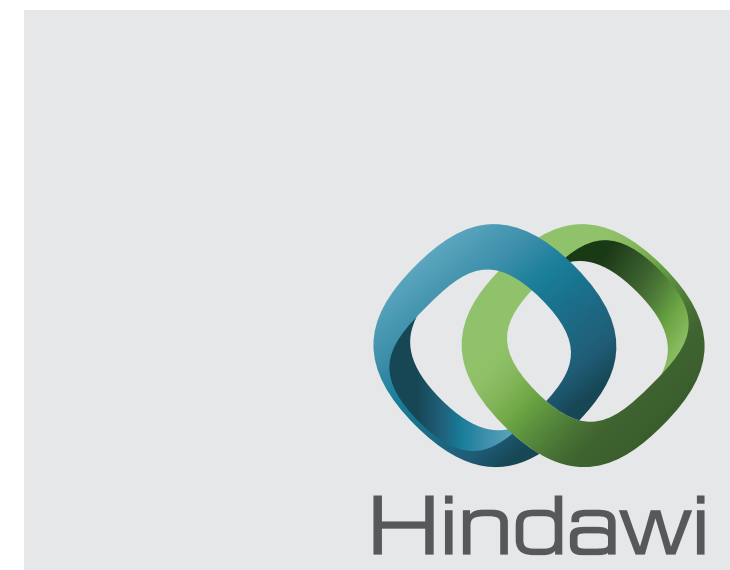

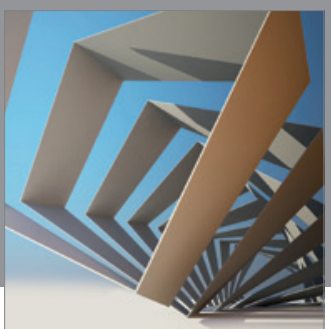

Rotating

Machinery
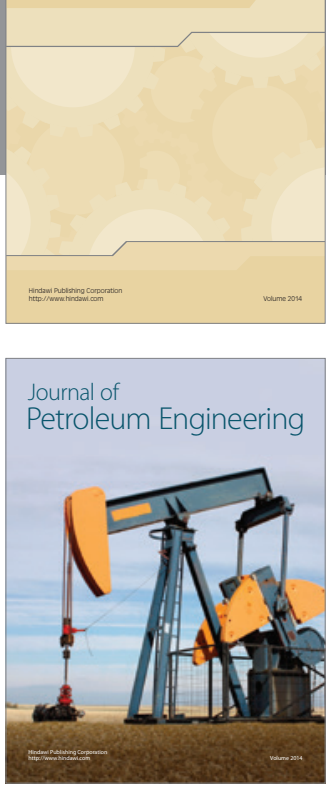

Journal of

Solar Energy
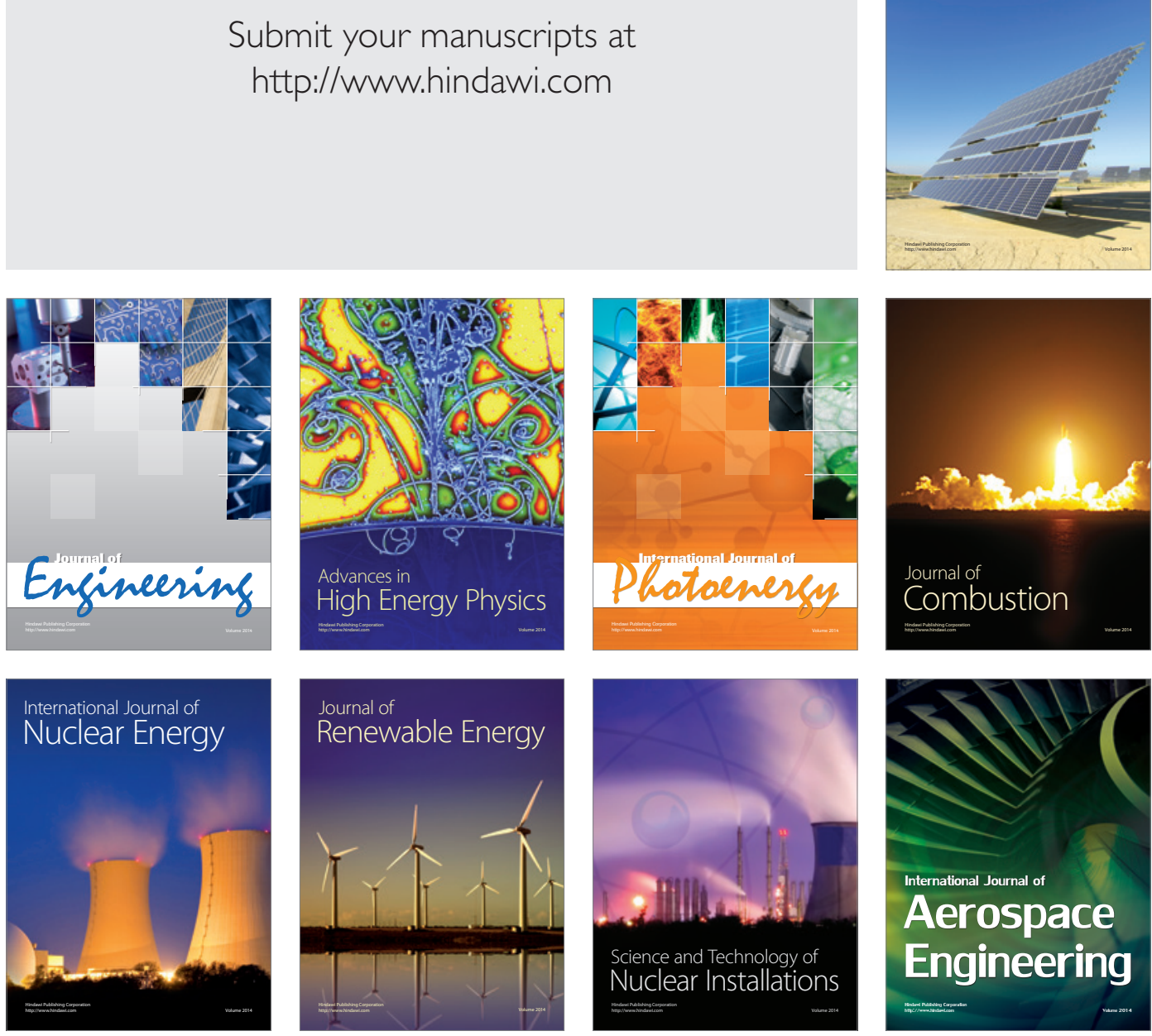